\title{
The Convergence of Modern Scientific and Traditional Earth Ways of Knowing, with Implications for Global Education
}

\author{
Troy Hassan Shepherd \\ Elementary Teachers Federation of Ontario
}

\begin{abstract}
Globalization and colonialism has impacted and continues to decimate nature based cultures around the world. As we become a global community, it is valuable to interrogate our epistemologies in the West and look for opportunities to merge with Earth ways of knowing in order to create more equitable, inclusive and who listic ways of knowing, for us all. This inquiry is intended to create a framework for the creation of a new kind of education, one that is inclusive of both modern and traditional Earth ways, and is relevant to the needs and dreams of the people and our planet today, and for generations to come.
\end{abstract}

\section{Introduction}

As a young boy growing up in Trinidad, I remember the words of my grandmother (now residing in the ancestral realm), who urged, "Son, study yuh book." As my main caregiver, she faithfully encouraged me to learn about various aspects of life, intellectual, physical, emotional and spiritual. She championed my academic accomplishments. While exercising, praying, healthy eating, sound sleeping and paying attention to dreams were a natural part of our lifestyle. Honoring and practicing multiple spiritual faiths was also a norm. In secondary school, modern science became my main way of viewing the world, replacing former beliefs. I learned about Charles Darwin's theory of evolution and this new evidence was not able to coexist (in my binary mind) with former creationist paradigms. Later, while attending university, I listened to an autobiographical poem composed by a classmate, who spoke of her belief in both God and evolution. The idea intrigued and inspired me to converge multiple ways of knowing within myself. Her creative expression began to awaken an inner knowing and curiosity about the integration of various epistemologies.

After graduating with a Bachelor of Science and a Bachelor of Commerce, I combined the disciplines working as a pharmaceutical sales representative. During this time, I was initiated with what I call 'The Dark Decade of the Soul.' I was hospitalized and later diagnosed with bipolar disorder. At one stage, I felt like I carried all the terror, despair and endless emptiness of the entire universe weighing upon my consciousness, which grew more and more agonizing by each infinitesimal instant and lasted for eternity. I came to learn that I experienced a spiritual death and renaissance, which were reflected in my nightly dreams. Fortunately, I was blessed to have been supported and introduced to a mentor, who healed with dream work, holistic health care and homeopathy. My loving significant other at the time and caring family were instrumental in helping me to stay in this world. Since the year 2000, I have continued to work with various healers in order to promote well-being and learning in an integrative way. I am fortunate to have been initiated by gifted elders including Heidi McBratney, Malidoma Somé, Mandaza Kandemwe and Gail Whitlow. I am transformed, after initiations using the technology of the Laika of Peru, the Dagara of Burkina Faso and the Sanusis of South Africa.

Working as a teacher for the past decade has afforded opportunities to merge and apply traditional Earth ways and modern education, with great success. While completing a Masters of Education, I coined the term Inclusive Education Process (I.E.P.), which I define as the continuous improvement, innovation and application of technologies which incorporate the body, mind, psyche and spirit, in order to enhance achievement, well-being, learning for all, learning of all and learning as all. This approach speaks to the self and the Self. It suggests that when an individual is self-actualizing, their whole self as well as the collective Self benefits from this process. This research will be looking at how various traditional Earth ways technologies from around the globe can be merged with modern education, redefining what it means to be educated.

\section{The Need for Change in Education}

Bono from U2 sings, "We're One, but we're not the same" [1]. At the most fundamental level, we are One- connected through all of time, all of space and all of matter. I explain this concept mathematically by comparing the idea of 'Undefined' representing "One", and quotients like $\underline{1}, \underline{2}, \underline{3} \ldots \infty$ representing "not the same". All of $0 \quad 0 \quad 0 \quad 0$ these quotients are Undefined (One), yet they are all different at the same time (not the same).

The principle of entanglement in quantum physics supports this oneness assertion. Experiments show that two electrons that were closely associated seem to be connected in some way even when separated by great distances. I recently received a vision of this oneness that seemed to come from a 
future time, back to me as a present, in the present. I felt that humanity was One. We all had the genes of all the ancestors of the planet and looked similar. I saw that there were no outer wars, but there was inner conflict. In the collective unconscious of the future human, we reside as their ancestors. When a person of this future time feels suicidal, it is because we (their ancestors who live in the present) are warring in their collective unconscious - their Nazi ancestor wanting to harm their Jewish ancestor, their $\mathrm{Ku}$ Klux Klan self, fighting their Black Panther self. As we move towards this race of oneness in the body, mind and heart, the age old story of Romeo and Juliet will continue to have relevance, as proverbial Capulets and Montagues battle to maintain the old ways of separation, supremacy, hatred and fear.

Many leaders of nature based cultures around the world continue to draw our attention to the importance of caring for our planet, ourselves and each other. Some Elders are able to hear the voice of Gaia, the plants and the animals. They speak of this time in human history as being unprecedented and of a need to respect our Mother Earth and all life forms on our planet. These ideas seem contrary to that of the dominant culture of the West, which mainly views the Earth as 'just a dead thing, you can claim' [2]. In order for us to continue to live harmoniously on our planet, it is valuable for the dominant modern culture to espouse the wisdom of traditional Earth cultures.

As we globalize, we must realize the need to indigenize. Since education is the main vehicle for transmitting cultural values, and as Nelson Mandela said, '... the most powerful weapon which you can use to change the world', there must be a new vision for education in the $21^{\text {st }}$ century and beyond. It is widely known that our overall health affects our ability to learn. Nature based cultures of the world have been deeply impacted by colonization and globalization. According to a report published by Canadian Institutes of Health Research..."Significant health disparities exist between Aboriginal and non-Aboriginal Canadians. Aboriginal communities continue to struggle with many critical health issues." The socioeconomic, political and cultural inequities that impact the health of individuals and communities are often referred to as "social determinants of health" In Canada and worldwide, disparities in social determinants of health and corresponding health outcomes persist. Canada's 2006 Census data shows that in 2005, fewer Aboriginal people between the ages of 25 and 34 earned a high school diploma (68.1\%)than nonAboriginal people $(90.0 \%)$ (Indian and Northern Affairs Canada, 2009)[4]. The median income for Aboriginal people was almost $\$ 10,000$ lower $(\$ 16,752)$ than for non- Aboriginal people $(\$ 25,955)$ [4].
With a common colonial history and resulting socioeconomic, cultural and political marginalization, there are profound health impacts on indigenous peoples in Canada and their counterparts around the world [6].

In Canada and other parts of the world, indigenous peoples are affected by major health problems at rates significantly higher than non-indigenous populations [4]. Some health issues include "high infant and young child mortality; high maternal morbidity and mortality; heavy infectious disease burdens; malnutrition and stunted growth; shortened life expectancy; diseases and death associated with cigarette smoking; social problems, illnesses and deaths linked to misuse of alcohol and other drugs; accidents, poisonings, interpersonal violence, homicide and suicide." Indigenous as well as other marginalized communities suffer similar outcomes [4].

\section{All Humans are Indigenous to this Planet}

All humans are Indigenous to a place on this planet. As equity involves allowing people what they need in order to succeed, in the spirit of the UN law for the Universal Declaration of Rights of Indigenous Peoples, Indigenous rights must be extended to all who suffer similarly due to colonialism. Colonialism wounds us all, so the benefits of indigenous pistemologies must be used to help heal us all. As a black person from the Caribbean, I recognize that my indigeneity is in Africa, and that peoples of the diasporas suffer similar educational, health and economic disparities.

Some theorists highlight challenges existing in our current system relating to marginalized communities in the West. In relation to postmodernist theory, part of its definition expressed by Lyotard in Postmodern Education, is an aspect which resonated with me:

"Lyotard has described postmodernism as a rejection of grand narratives..... and any other form of totalizing thought. In his view, the meaning of postmodernism is inextricably related to the changing conditions of knowledge and technology that are producing forms of knowledge and technology that are undermining the old habits, bonds and social practices of modernity" [8].

This was appealing in that, as a member of asubaltern group, I am motivated to put forth a counter narrative to contest the current dominant, hegemonic master narrative that oppresses my indigenous self, and yet I benefit from. By benefiting from this system, I am speaking about my privileges- including my male privileged self, cis-male privileged self, an able-bodied privileged self, an able-minded privileged self, an age of 
majority privileged self, a First World citizen privileged self and a heterosexual privileged self, for example. I intend to use these advantages to help create a fairer and just world for all.

An idea expressed by Michael Apple that was striking to me was the concept of education and its ability to socialize, reinforces the inequitable power structures that exist in society. Michael Apple in Ideology and Educational Reform states: "I shall argue that it is difficult to think through the past and present problems of the form and content of curriculum without attempting to uncover the complex nexus linking cultural and economic reproduction together" Giroux et al state "Theorist such as Pierre Bourdieu, Basil Bernstein, Paulo Freire, Michael Apple and others have investigated the relationship between power and culture, arguing that the culture transmitted by the school is related to various cultures that makeup the wider society, in that it confirms and sustains the culture of the dominant groups while marginalizing and silencing the cultures of subordinate groups of students" [8] [9].

Another aspect of this idea of education as social machine is echoed by Apple who argues that high status knowledge is scarce and that this scarcity is linked to its instrumentality. He states that schools 'process' knowledge and people as well and that in our economy the optimal unemployment rate approximately $4 \%-6 \%$. He compares this to the optimal supply and demand for knowledge. Optimal in that it benefits the ruling classes and does not consider underemployment and higher rates for blacks. With high status knowledge, it is not evenly distributed throughout the population in general. This uneven distribution makes high-status knowledge most instrumental. As a result, low levels of achievement by marginal groups may be accepted. Production of knowledge as a scarce commodity is more valuable to the economy than its equitable distribution [9]. 'The economy' should be more appropriately called the 'the ruling classes economy', as everyone is not yet free to trade their gifts and talents to earn a fair living.

I agree with the views of these theorists and go further to say that in my experience of education; I have found that it prepared me to be the archetypal student -a programmed, petrified, paper-producing, professional prostitute who is more interested in promotion up the corporate ladder than in the promotion of well-being and equity. I am trained to sell my conscience and my creed for a career of fear and greed. When I was in elementary school, I learned that the teacher was the boss and had the right to emotionally and physically punish me. Later in postsecondary, I was told that to get good marks I was to look at the professor's research and write according to their interest in order to get high grades. I learned to trade my conscience for marks. In the work world, the mindset of the high achieving archetypal student is welcomed, as the new report card becomes the performance evaluation. Since we are programmed to sell our own conscience for marks, it is now an easy shift for us to sell our souls for money. Given that The Archetypal Corporation's sole purpose is to profitize, the question then becomes, 'Who is the archetypal pimp that procures these precious souls for a pretty profit?' The point here is that any system can be discounted, devalued and demonized, as we all have light and darkness in our souls. The hope is that both traditional Earth ways and modern technologies will instead be legitimized, merged and honored for the deep wisdoms that they both carry. I trust that we will all be able to benefit from incorporating traditional Earth ways of knowing. The SAMR model was popularized by Dr. Ruben Puentedura (see Figure 1).

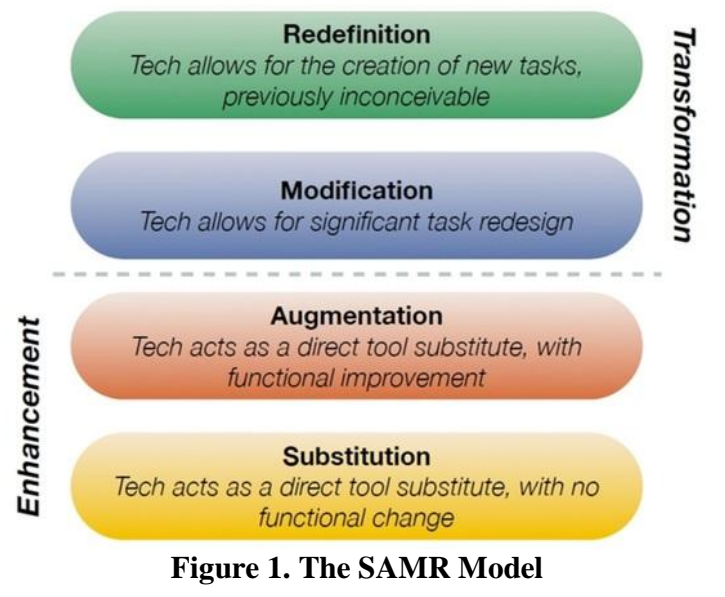

It is used to describe how technology can be implemented in teaching and learning. S stands for Substitution, A stands for Augmentation, M is for Modification and $\mathrm{R}$ is for Redefinition. In order to meet our equity, well-being and quest for excellence and public trust goals, we must use the SAMR model with traditional Earth ways to redefine what it means to be educated-where Learning for All includes Learning of All and Learning as All.

\section{Nature Based Views on Mental Health}

Leader? sees vision in the mind's eye. Lunatic? hears voices of said vision in the mind's ear.

Irony? The coloniality of reality.

At the top of our governance in the West, the virtues of Judeo-Christianity are heralded, ironically, healers, usually the ones with mental health challenges are devoured by the fast, furious fearfactory of our modern world. For example, in Ontario the Education Act states that the teacher's duties are:

(c) to inculcate by precept and example respect for religion and the principles of Judaeo- 
Christian morality and the highest regard for truth, justice, loyalty, love of country, humanity, benevolence, sobriety, industry, frugality, purity, temperance and all other virtues;

As well, in all religions there is a person who possesses magical powers and communicates with a realm that others did not see. Ironically, if the avatars of Judeo-Christianity returned to us in the body today and made claims of parting the waters, walking on the waters and turning the waters into wine, they might be swiftly sedated, stigmatized, stereotyped, suggested suicide to, shamed and sentenced to sacrifice.

Many nature based cultures have a differing perspective from the West on mental health. Ohky Simine Forest in her book Dreaming the Council Ways, writes "Natives say that crazy people are touched by the great spirit" [10]. Malidoma Somé, states that psychosis signals "the birth of a healer" 7 . While the Shamanistic Theory of Schizophrenia suggests that in indigenous cultures:

"..the abnormal experience (shamanism) is typically beneficial to the individual, cognitively and affectively; he is regarded as one with expanded consciousness. In a culture that does not provide referential guides for comprehending this kind of crisis experience, the individual (schizophrenic) typically undergoes an intensification of his suffering over and above his original anxieties" [3].

With this in mind, it may be valuable to inculcate by precept, percept and example. This traditional perspective highlights the need to create cultural referential guides in the west for supporting citizens with these types of experiences.

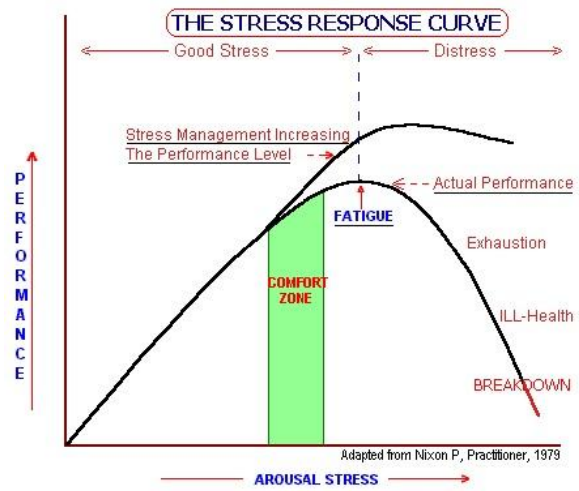

Figure 2. The Stress Response Curve

Another part of the lawin Ontario states that teachers are to act as judicious parents (in loco parentis). The latin words translate to 'in place of parent.' Ironically, in some education cultures hugs are discouraged and drugs are encouraged -even though it is widely known that the result of insufficient tactile stimulation is failure to thrive.

What kind of parent maintains a culture of fear, withholds hugs, promotes drugs, while expecting the outcome to be higher-order thinking? The education system does all this, while knowing that too much stress stimulates the fight or flight system otherwise known as the HPA axis, consisting of the hypothalamus, pituitary in the brain and adrenal glands atop the kidneys, negatively impacting cognitive ability. See figure 2- The Stress Response Curve.

This is not in loco parentis, it is closer to 'loco en la cabesa!' Fostering a climate of well-being and compassion helps to heal us all.

\section{Creating a Culture of Care}

I remember feeling agoraphobic and not wanting to go out because large groups of people seemed to exude an intense energy that felt painful to me. I believe that some people with mental illness are able to interpret the emotional frequencies of others. If someone has a wounded leg and needs to take the elevator, most everyone understands this need. No one in their right mind would hit the person's wound with a baseball bat. If an assailant did do this, most reasonable people would understand if the injured person responded in self-defense.

However, if someone has a wounded psyche, their need for self-actualization and accommodation is frequently overlooked. The fact that the self or psyche is invisible to the naked eye of most can cause challenges for others in understanding their needs for accommodation and self-actualization. Some with wounded psyches may have unique needs to attend to, and a hostile institutional culture may act like an assaulting baseball bat to the sensitive person's psyche.

In the book King, Warrior, Magician, Lover Rediscovering the Archetypes of the Mature Masculine, Moore and Gillette write, "If the king does not live "in the Tao" then nothing will go right for his people, or for the kingdom as a whole. The realm will languish, the Center, which the king represents, will not hold, and the kingdom will be ripe for rebellion"[20]. Rather than concentrated power at the top of institutions, Bruce Lipton and Steve Bhaerman refer to Surowieki's research findings that decentralization, independence and diversity influence the accuracy of a group's shared wisdom [29].

\section{The Law and Indigenous Epistemology}

Abraham Maslow conceptualized the Hierarchy of Needs, see Fig. 3. The definition of a 'need' is that if someone doesn't have them met, they die. It is more obvious to observe the violence of restricting the physiological need for air. However, the subtle violence of restricting the need for self-actualization may not be as evident. Indigenous peoples impacted by colonialism and those in the diasporashave unique 
needs that must be met. I believe that if peoples are allowed to meet these needs, we will see a more prosperous world for us all.

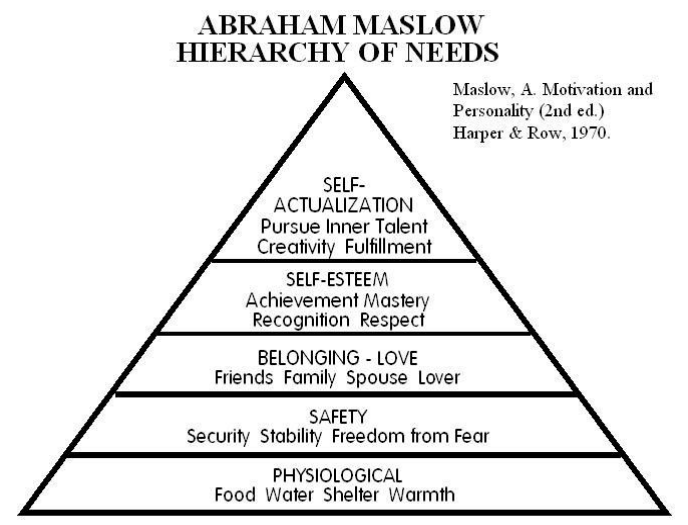

Figure 3. Maslow's Hierarchy of Needs

Article 25 of the Universal Declaration of Human Rights states.

1) Everyone has the right to a standard of living adequate for the health and wellbeing of himself and of his family, including food, clothing, housing and medical care and necessary social services, and the right to security in the event of unemployment, sickness, disability, widowhood, old age or other lack of livelihood in circumstances beyond his control.

As such, it would be a violation of human rights for organizations to disallow their employees the need to self-actualize, to seek well-being and necessary medical care. This need for care may be defined by the individual.

In Canada, the Ontario Human Rights Commission states that:

"Disabilities are also socially constructed" and that "Human rights decision-makers and organizations should consider how people with mental health issues or addictions subjectively define their own experiences and related needs" [21].

This means that if a person chooses to define their mental health 'disability' in indigenous terms, the organization should consider the individual's own definition.

Due to the ubiquity of coloniality, and in the spirit of universality of the Universal Declaration of the Rights of Indigenous Peoples, colonized peoples in the diasporas must be able to make claims under this law. Since colonialism impacts the oppressed as well as the oppressor, and due to the universality of application of indigenous principles, everyone must be allowed to benefit from the applications of indigenous epistemologies. The Universal
Declaration of the Rights of Indigenous Peoples states:

Concerned that indigenous peoples have suffered from historic injustices as a result of, inter alia, their colonization and dispossession of their lands, territories and resources, thus preventing them from exercising, in particular, their right to development in accordance with their own needs and interests,

In addition, Article 5 states,

Indigenous peoples have the right to maintain and strengthen their distinct political, legal, economic, social and cultural institutions, while retaining their right to participate fully, if they so choose, in the political, economic, social and cultural life of the State.

As such, peoples of the diasporas must be allowed to restore their epistemologies and have their ways of knowing be recognized and respected by the respective States.

In regards to education, the Convention on Rights of the Child state:

\section{Article 30}

In those States in which ethnic, religious or linguistic minorities or persons of indigenous origin exist, a child belonging to such a minority or who is indigenous shall not be denied the right, in community with other members of his or her group, to enjoy his or her own culture, to profess and practise his or her own religion, or to use his or her own language.

These rights provide for all children to learn about Indigenous ways of knowing. Allowing students to learn about ancient ways of knowing will help them to greater levels of well-being and achievement.

\section{The Wounded Healer}

My mentors have said that we all walk the path of the wounded healer, since life wounds us all. Rumi states "The wound is where the Light enters you" Some of us are more deeply wounded than others and have more healing ability, as a result. I wrote this poem to express my feelings about these wounded healers. Mr. Wendal is song that was created by a group called Arrested Development which spoke of the wisdom of the ones we refer to as a 'bum.' This poem continues this discussion.

\section{The Wounded Healer}

Mr. Wendel, You'd a healah not a stealah, not a drug dealah, even though this world don't feel ya.

I know you have the fitness, you's a witness to the thickness of this soul sickness.

Your goal to ensoul and enshrine the mystery of the Divine.

You know the universe inside, where angels and demons hide. So pour the feelings from your heart. Embody them in your art. You will come to the section where you see your reflection. I will come to the section where I face my reflection. Even though I am The Royal Guelph, healer, heal thyself. Chorus

Healer, heal thyself. Healer, heal thyself. 
Healer, heal thyself. Healer, heal thyself

Healer, heal thyself, Healer, heal thyself.

Verse

I shed my past to the South and I real-eyes

that I bridge West to Infinitize,

I'm so glad Humming Bird finally found her prize.

We see the Eagle in the East with our open eyes

And Patcha Mama being Heaven dressing in dis-guys

is a gift that I'm getting giving from the skies.

is a gift that I'm getting giving from the skies.

The truth that hurts is a paradox.

I gift it to my kuyas and my rocks.

To this life I sense there is no end.

My dark side, I must befriend.

Chorus

Even though I am The Royal Guelph, healer, heal thyself.

Healer, heal thyself. Healer, heal thyself.

Bridge

It's all about the How, cuz the journey is the Now. And It's all

about the Now cuz the journey is the How.

Chorus

Even though I am The Royal Guelph, healer, heal thyself.

Healer, heal thyself. Healer, heal thyself.

\section{All Creation Stories are True- The Truth is a Paradox}

The Elders of the Red Nation state that "There are many Creation stories. We are told that every Creation story is true" [5]. In an article by Native American poet, Kimberly Blaser titled Writing Voices Speaking: Native Authors Authors and Oral Aesthetic, Blaesar highlights this multiple points of view. She states "Native authors may offer their story through multiple voices to create a cacophony of reality; range freely through the conventional boundaries of time and space to depict the interconnections of myth and present experience, of spirit and flesh; resist the arbitrary 'ending' of story to embody the continuance of life and telling; or bend their stories back on themselves, shape their tellings around circular images, the weavings, webs or 'sacred concencricities' of their cultural and aesthetic experiences"[25]. All creation stories are true, yet, a paradox may exist in this fact.

Truth is a paradox. I explain this as follows: We can divide time into days, hours, minutes, seconds, milliseconds and we and keep diving forever, since time never stops. Yet we can see the stoppage of time (a Now) in a still photo. We can also leave time undivided and view it as one eternal moment (also a Now). This is the same with space. We may divide space with meters to nanometers and keep dividing forever, or we can leave space undivided as one ubiquitous 'Here'. The Earth continually rotates on its axis and revolves around the Sun while moving through space, so 'here' is never 'here' with respect to all of space and now is never now with respect to all of time. As such, there is a here and a now, yet there isn't.

The famous mythologist Joseph Campbell created the Monomyth, which professes a common core to all mythological stories of humanity. People of our world must find peace in this paradoxical mystery as these stories are combined with modern science to create a solitary, secular, spiritual science. This convergence process is occurring at organizations such as the Mind \&Life Institute, who are committed to 'scientific understanding as a way to reduce suffering and promote human flourishing.' The indigenous people of the world must revitalize their ways of knowing and value them, so as to make the merger valuable to us all.

\section{Science as Faith}

With all due respect to marvels of modern science- including modern medicine, space travel and communication technologies to name a few, I argue that modern science is but one way of knowing that presents itself as the universal, neutral, solitary, supreme and incontestable, only way of validating The Absolute Truth. Some believe that modern science deserves this privileged place, while others believe that there are limits to modern science, just as there are limits in calculus. It may be worthwhile to merge with other ways of knowing in order to create a more wholistic and pluraversal way of viewing our world- creating epistemological equity. Geroux and Aronowitz in The Politics of Literacy p35 state:

..., science is interested only in knowledge that can be derived from mathematics andexperiment. Scientism which depends on theories, thinking,analysis and having aworldwide monopoly on producing and legitimizing truth, this position of power is used to recreate and sustain the hegemonic power structures globally" [8].

Emeagwali \& Dei, and Shizha, state that, "Unfortunately, rather than western science acknowledging the multiple, collaborative and accumulative dimensions of knowledge, western scholars and scientists attempted to either dismiss, devalue or negate indigenous knowledge as being not worthy of scholarly engagement [24].

I agree with these statements and argue that not everything in the universe can be mathematically measured or experimented upon. Modern science has the benefit of being associated with terms like 'exact science' and 'scientific proof'. However, I argue that mathematics- the main tool for the exactness of modern science depends on the imagination and doesn't have proof of its Self. For example, Imaginary numbers (I) (see figure 4) are numbers that when squared give a negative result $\mathrm{i}^{2}=-1$. The number system also contains infinite undefined quotients, like $1 / \infty$ and $\mathrm{i} / 0$. How could a system with infinite imaginary numbers and infinite undefined quotients be solely responsible for defining 'Everythingness-ing'?!Moreover, if we only have 5 senses as modern science claims, with what sense do we sense imaginary numbers? Most would agree 
that limiting us to only 5 senses makes absolutely no. sense.

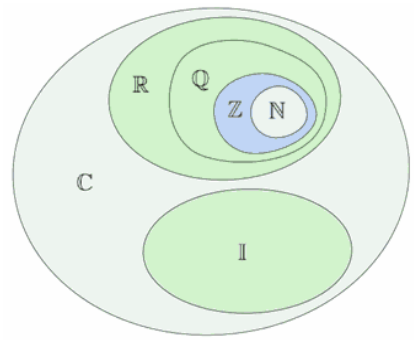

Figure 4. Number Sets

As well, Scientism as a faith uses numbers that we cannot measure with our five senses to prove the existence of a Big Bang creation story and that of subatomic particle-waves and strings that we cannot observe with our five senses. No one has ever seen, heard, smelled, tasted nor felt a neutrino. Yet, it is considered scientific fact that neutrinos exist. Scientific evidence proves that electrons are appearing and disappearing out of nothing. These methods and conclusions sound more like faith and magic than science to me. Modern science as a religion, believes in the God of RandomNothingness, venerates the promised land of Absolute Truth and Matter, prays to the ResearchFunding deities, meditates on The Scientific Method, reveres saints like Newton and Darwin, and has absolute faith in The Holy Book of Numbers. With such strong faith in Numbers and such compelling evidence of entanglement, it is challenging to know that all modern scientists don't yet believe that we are all One.

Since $\mathrm{i}^{2}=-1$, this means that numbers and letters are both symbols that may represent the same concept. If modern science is uncomfortable with the letters in the word 'Spirit', we might choose to use the words 'Conscious Energy Field' or even Spi $\sqrt{ } i^{2}+$ or maybe S. $\pi \mathrm{rI}$.T. The former spelling is due to mathematical fact that the square root of $i^{2}=i$, while the root $\operatorname{sign}(\sqrt{ })$ represents the letter $r$ and the addition sign $(+)$ represents the letter $t$. In the latter spelling of the word 'Spirit', the mathematical symbol $\pi$ stands for the letters $p$ and $i$. In this version of the word, we have $S$ representing Science, I.T. representing Information Technology and $\pi$ representing Mathematics. This may help us to think of Spirit differently.

In the book Biology of Belief, Bruce Lipton states "The Carnegie Foundation published the Flexner Report in 1910 that called for all medical practices to be based on proven science." ${ }^{26}$ This report was not inclusive of indigenous science. Additionally, the heavy dependence on thinking and theories and meta-therories about theory, to the exclusion of other ways of knowing may be due to the embodiment of Decarte's philosophical statement- "I think therefore I am." Our new philosophy might be, "I think therefore I am", "I feel therefore I am," "I am that, I AM"- inclusive of body, mind and spirit. I'm sure that most would agree that it would be a strange, sterile and static world if the only way of knowing the degree to which your fiancé loved you was to perform a repeatable, peer-reviewed, double-blind, randomized, controlled trial. Since we can view Orthodox Modern Scientism as a faith, by solely funding this epistemology and oppressing other cultures (epistemologies), many States have created and continue to maintain a systemic barrier to equity, well-being, achievement and public trust - namely, the institutionalization of the unfair and illegal practice of faith-as-an-ism.

\section{One Culture's Science is Another's Magic}

In the book, Mystery of the White Lions, Credo Mutwa is quoted to say, "What we call magic today was the science of ancient people" [21]. This perspective can be explained by again looking at mathematics. We cannot observe neither zero, infinity, negative infinity nor an imaginary number with our five senses because they are concepts that are first presented in the mind and $\boldsymbol{r} \boldsymbol{e}$-presented or symbolized in multiple media. The word five is emphasized because some indigenous people believe that humans actually have 12 senses. In some indigenous cultures, spiritual communication from other realms are presented in the psyche through dreams, intuitions, instincts and visions and represented in multiple media like cowrie shells, bones, tarot cards, tea leaves and other divining instruments.

If an indigenous villager who has not been exposed to the modern world and is not print-literate sees a textbook of rocket science and told that this technology could take a huge shuttle to Mars, this might seem magical to them. Most of the laity of our modern world do not understand topics like rocket science and electronic engineering. However, these topics are not considered to be 'magical' by modern westerners, but 'scientific'. Just as the scientific miracles of the west may appear to be magical to indigenous peoples, the science of indigenous peoples, some of which include time travel, transmogrify, telepathy and teleportation may seem magical to modern westerners as well.

The spirits that indigenous peoples speak of are analogous to the archetypes in psychology. They have been likened to energy fields. Most are unable to see a magnetic field, however we all can feel its effects. We can also see the pattern it creates when we sprinkle iron filings. See figure 5. The matter of our bodies is like the iron filings and our spirits are like magnetic fields. The spirits or archetypes act like magnetic fields which can order matter into specific patterns. An approach to well-being and education which includes both a scientific 
biochemical and an indigenous archetypal or spiritual approach would be more effective, as a wholistic approach gives deeper insight.

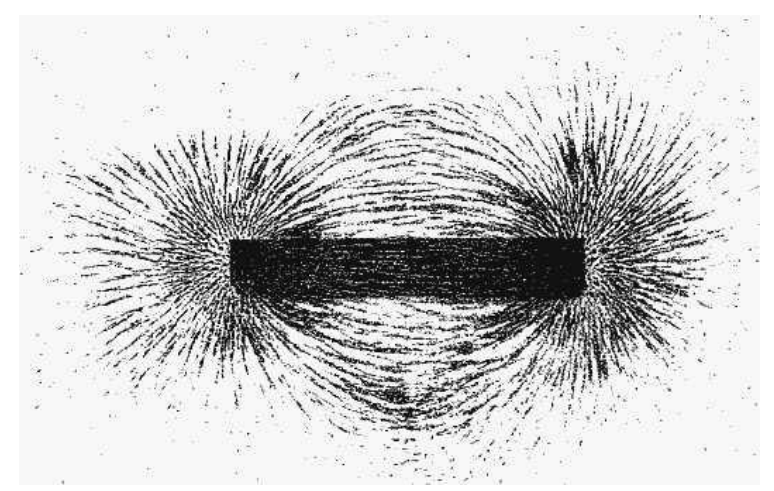

Figure 5.A Magnetic Field

Some modern scientists like Arthur Zajonc, $\mathrm{PhD}$ are beginning to think more "carefully and subtly" about our world [28]. The idea of intrinsic subjectivity in physics realizes that everything in the universe appears in relationship or in context. This means that it is important for us to listen to and value each other's perspectives. Together, relativity and entanglement may be saying that we are all relatives. Scientist and feminist philosopher, Karen Barad is quoted to say "...just like position, momentum, wave and particle, time itself only makes sense in the context of particular phenomena."

The Capacity Building Series ${ }^{27}$ states that, "Culture is about ways of knowing. "If culture is about ways of knowing, shouldn't multiculturalism be about multiple ways of knowing? Fortunately, In Canada in 1998, the federal government passed Bill C-93, which "imbued the principle of racial and cultural equality with the force of law" [22] [23].

\section{Physics and Metaphysics}

"The more I study physics, the more I'm drawn to metaphysics." - Albert Einstein

The merger of physics and metaphysics is a model for the convergence of indigenous knowledge systems and modern science. I have reflected on the meeting of metaphysics and physics and extend these thoughts here in order to exemplify this convergence thinking.

The first example relates the Big Bang theory to the creation story in the Bible. At the subatomic level, the smaller the particles become, the more potential energy is involved. When we boil water there is not much energy involved, as we are breaking intermolecular bonds -bonds between molecules. When we get one level smaller to an atom, we have the power to blow up a city. An even smaller particle (the nuclei) emits the energy of the sun through the process of nuclear fusion. The smaller the subatomic particle gets, the more potential energy is involved. I suggest that Nothingness exploded, as in the Big Bang, and had the power to create Everythingnessing. Just as the Tao "does nothing yet leaves nothing undone." This is similar to the Bible King James version Genesis 1:2 which states that:

And the earth was without form, and void; and darkness was upon the face of the deep.

I liken this void and darkness to the Nothingness from which electrons appear. From a shamanic perspective, Nothingness is a place of creation. Nothingness may be analogous to the Zero Point Field. The Zero Point Field is the energy that exists at absolute zero. I was taught that creation continues and that we are participating in the creation of the universe. The idea the creation continues is reflected in the infinite nature of the number system. Infinity is a concept that means the number system keeps going on without an end- proving that reality is a process.

\section{Physics, Metaphysics and Reflections on A New Earth}

As human consciousness continues to evolve, some authors have created works that are intended to assist in this evolutionary process. I reflect on my reading of the book, A New Earth in order to share another example of the merger of physics and metaphysics. Eckhart states that the main purpose of the book is to "bring about a shift in consciousness, that is to say awaken."

Eckhart writes about the "frequency holders"12 saying, "the outward movement into form does not express itself with equal intensity in all people." I relate this assertion to the Newtonian equation describing the acceleration due to gravity. The equation is:

$$
\mathbf{F}=\boldsymbol{m} \boldsymbol{g}
$$

$\mathbf{F}$ is the gravitational force that is pulling the object down towards the Earth, and is directly proportional to (m) (mass of the object). Acceleration due to gravity $(\mathbf{g})$ is a constant $\left(9.8 \mathrm{~m} / \mathrm{s}^{2}\right.$ ) . $\mathbf{F}$ and $\boldsymbol{m}$ are directly proportional while $\mathbf{g}$ is a constant. The acceleration due to gravity (g) can be analogous to the universal, ubiquitous, omniscient, omnipotent, conscious, mysterious un-manifest energy that is being us and expressing through all of space and time, while $\mathbf{F}$ is how this energy is expressed outwardly in physical form. How intensely this $\mathbf{F}$ is expressed depends upon your $\boldsymbol{m}$. Your $\boldsymbol{m}$ is your mysterious composition, which is determined by your past lives, future lives, presence, karma, dharma and a host of unknown and unknowable factors. In the case of messengers like Buddha and Christ, and others, not all were known, their $\boldsymbol{m}$ was composed such that their $\mathbf{F}$ was intensely expressed in this dimension.

Classically, 
Form $=$ mattered $g \cdot$ o.d.ness.

Quantum mechanically,

Field $=\boldsymbol{m}$ athematical $\boldsymbol{g}$.o.d.ness.

Frequency $=$ mysterious $g$.o.d.ness

And metaphysically,

$\boldsymbol{F}$ orgiveness $=\boldsymbol{m}$ agical $\boldsymbol{g}$.o.d.ness.

$\boldsymbol{F}$ un $=\boldsymbol{m}$ aking $\boldsymbol{g}$. o.d.ness

$\boldsymbol{F}$ ear $=\boldsymbol{m}$ ad g.o.d.ness

$\boldsymbol{F}$ aith $=\boldsymbol{m}$ eaningful g.o.d.ness

Freedom $=$ mindful g.o.d.ness

Where g.o.d. may stand for whatever one wishes e.g., gateway of discovering, great one developing, good orderly direction, great omniscient deity, gracious omnipotent divinity, gentle outstanding dancing, generative objective dawning, gracious observant dimension, etc. Your $\boldsymbol{m i s}$ unique to you and as oneself-actualizes and fully expresses one's unique gifts, all of humanity benefits.

The classical equations describe Form and are analogous to the particle and wave states of Matter. The quantum equation describing the Field is analogous to the non-locality of fields in quantum mechanics and the Mind. The metaphysical equation describing Forgiveness is referring to Meaning. Finally, we have Metaphor and the great Mystery, which is forever mysterious.

Einstein's equation $\mathbf{E}=\mathbf{m} \mathbf{C}^{\mathbf{2}}$ and Newton's $\mathbf{F}=$ $\mathbf{m g}$ are related in a number of ways. In Einstein's equation $\boldsymbol{E}$ stand for energy, $\boldsymbol{m}$ stands for mass and $\boldsymbol{C}$ is the speed of light. In Einstein's equation, $\boldsymbol{E}$ and $\boldsymbol{m}$ are directly proportional, while $\boldsymbol{C}^{\mathbf{2}}$ is a constant. It is saying that when we accelerate matter to the speed of light squared, it becomes energy. I add, that when Universal energy is slowed down below the speed of light squared, it transforms into matter. Both $\boldsymbol{F}$ and $\boldsymbol{E}$ are directly proportional to $\boldsymbol{m}$, While $\boldsymbol{C}^{\mathbf{2}}$ and $\boldsymbol{g}$ are both constants. When we relate $\boldsymbol{F r e q u e n c y}=$ mysterious $\boldsymbol{g}$.o.d.ness to $\mathbf{E}=\mathbf{m} \mathbf{C}^{\mathbf{2}}$, it may become:

Entanglement $=\boldsymbol{m}$ athematical Consciousness $^{2}$

$\boldsymbol{E}$ ntanglement $=\boldsymbol{m}$ easuring Consciousness ${ }^{2}$

$\boldsymbol{E}$ motion $=\boldsymbol{m}$ oving $\boldsymbol{C o n s c i o u s n e s s}^{2}$

$\boldsymbol{E}$ nlightenment $=\boldsymbol{m}$ indful $\boldsymbol{C o n s c i o u s n e s s}^{2}$

Enlightenment $=$ mindful Compassion ${ }^{2}$

$\boldsymbol{E}$ arth $=\boldsymbol{m}$ ystical Consciousness ${ }^{2}$

$\boldsymbol{E}$ den $=\boldsymbol{m}$ ythical $\boldsymbol{C}_{\text {onsciousness }}{ }^{2}$

Enjoyment $=\boldsymbol{m}$ anufacturing Consciousness $^{2}$

$\boldsymbol{E}$ xistence $=\boldsymbol{m}$ irroring $\boldsymbol{C o n s c i o u s n e s s}^{2}$,

$\boldsymbol{E}$ mbodiment $=\boldsymbol{m}$ agnetic $\boldsymbol{C}$ onsciousness ${ }^{2}$,

where Consciousness can be whatever one wishes (w.o.w.)

Another way that these equations are related is that they can give us some insight into our nature as humans. If we express both equations in terms of $\boldsymbol{m}$, we have

$$
\underset{\mathrm{m}}{\boldsymbol{m}} \underline{\mathrm{F}} \text { and } \boldsymbol{m}=\underline{\mathrm{E}}
$$

Table 1 Multidimensional Mathematical Metaphysics

\begin{tabular}{|c|c|c|c|c|c|c|}
\hline $\begin{array}{l}\text { Dimensio } \\
\mathrm{n}\end{array}$ & $\begin{array}{l}\text { Con } \\
\text { cepts }\end{array}$ & Examples & Units & $\begin{array}{l}\text { World } \\
\text { Views }\end{array}$ & $\begin{array}{l}\text { Cons } \\
\text { cious } \\
\text { Leve } \\
\text { ls } \\
\end{array}$ & $\begin{array}{l}\text { Equatio } \\
\mathrm{n}\end{array}$ \\
\hline $\begin{array}{l}-\infty \\
\text { Great } \\
\text { omniscie } \\
\text { nt } \\
\text { dimensio } \\
\text { n } \\
\end{array}$ & $\begin{array}{l}\text { Mirr } \\
\text { ored } \\
\text { Myst } \\
\text { ery }\end{array}$ & $\begin{array}{l}\text { Mirrored } \\
\text { Spacetime } \\
\text { matter }\end{array}$ & $\begin{array}{l}\text { Mirr } \\
\text { ored } \\
\text { Unity }\end{array}$ & $\begin{array}{l}\text { Mirrored } \\
\text { Wholism }\end{array}$ & $\begin{array}{l}\text { Mirr } \\
\text { ored } \\
\text { Myst } \\
\text { ery }\end{array}$ & $\begin{array}{l}\mathrm{F}=\frac{\mathrm{Eg}}{\mathrm{C}^{2}} \\
\mathrm{E}=\frac{\mathrm{FC}}{\mathrm{g}}\end{array}$ \\
\hline . & . & & & & & \\
\hline . & . & & & & & \\
\hline. & . & & & & & \\
\hline 0 & $\begin{array}{l}\text { sym } \\
\text { bols }\end{array}$ & $\mathrm{A}, 1$, point & None & $\begin{array}{l}\text { Reductio } \\
\text { nism }\end{array}$ & $\begin{array}{l}\text { Meta } \\
\text { phor }\end{array}$ & \\
\hline 1 & $\begin{array}{l}\text { linea } \\
\mathrm{r}\end{array}$ & a line & $\mathrm{M}$ & & $\begin{array}{l}\text { Mea } \\
\text { ning }\end{array}$ & \\
\hline 2 & area & $\square$ a square & $\mathrm{m}^{2}$ & & & \\
\hline 3 & $\begin{array}{l}\text { volu } \\
\text { me }\end{array}$ & a cube & $\mathrm{m}^{3}$ & & Mind & \\
\hline 4 & mass & an object & $\mathrm{Kg}$ & & $\begin{array}{l}\text { Matt } \\
\text { er }\end{array}$ & $\mathrm{F}=\mathrm{mg}$ \\
\hline 5 & time & (1) circular & $\begin{array}{l}\text { secon } \\
\text { ds }\end{array}$ & & & \\
\hline 6 & $\begin{array}{l}\text { Forc } \\
\mathrm{e}\end{array}$ & gravity & $\begin{array}{l}\text { newt } \\
\text { ons }\end{array}$ & & & \\
\hline 7 & $\begin{array}{l}\text { Ener } \\
\text { gy }\end{array}$ & light, scalar & $\begin{array}{l}\text { joule } \\
\mathrm{s}\end{array}$ & & & $\mathrm{E}=\mathrm{mc}^{2}$ \\
\hline . & . & & . & & & \\
\hline . & . & . & . & & & \\
\hline $\begin{array}{l}\infty \\
\text { Great } \\
\text { omnipote } \\
\text { nt } \\
\text { dimensio } \\
\text { ning }\end{array}$ & $\begin{array}{l}\text { Myst } \\
\text { ery }\end{array}$ & $\begin{array}{l}\text { Spacetime } \\
\text { matter }\end{array}$ & Unity & Wholism & $\begin{array}{l}\text { Myst } \\
\text { ery }\end{array}$ & $\begin{array}{l}\mathrm{E}=\mathrm{F} C^{2} \\
\mathrm{~F}=\underline{\mathrm{E}} \mathrm{g} \\
\mathrm{C}^{2}\end{array}$ \\
\hline
\end{tabular}

E stands for energy and $\mathrm{C}$ is the speed of light. We can then equate the two expressions of

$$
\boldsymbol{m} \text {, getting } \underset{\mathrm{F}}{\mathrm{F}}=\underline{\mathrm{E}}
$$

If we then isolate $\mathrm{F}$, we have

$$
\mathrm{F}=\frac{\mathrm{Eg}}{\mathrm{C}^{2}}
$$

This equation may be looked at in a number of ways, the first is looking at $\mathbf{F}$ as a 'dark Force' and the right side of the equation as the light and g.o.d.ness. If we substitute a value of zero for $\mathrm{E}$, the value of $\mathbf{F}$ is 0 , which can be analogous to the light being off in binary computer language. If we substitute 1 for $\mathrm{E}$ we have $\mathbf{F}=$ g.o.d. / (speed of light $)^{2}$. In this case, let 'there be light' in binary computer language. There is also another option for values of $\mathrm{E}$-the qubit or quantum bit. This option highlights the infinite values between 0 and 1, e.g., $0.1,0.2,0.3 \ldots \infty$. This option could say that from an infinitely Universal perspective, there is neither good nor evil-we just are. Peace activist, Thich Nhat Hahn compares the darkness to the mud from which the flower grows. Another way of looking at this idea is looking at nature. From the gazelle's point of view, the lion is evil because the lion is trying to kill it and it's kin. From the lion's perspective, he may think, "What evil gazelles! They run away so fast 
and I need to get food for myself and my family!" From our perspective neither is good nor bad, it's just nature taking its

course.

In the case of $\mathbf{F}=\mathbf{m g}$,matter is with respect to 3D. The units $\mathrm{kg}$ represent matter and $\mathrm{m} \cdot \mathrm{s}^{-2}$ includes one dimension of space (metres) and two dimensions of time (seconds). In the case of $\mathbf{E}=$ $\mathbf{m C}^{2}$, we have matter with respect to four dimensions. Numbers exist in dimension zero ( 0-D), while a one dimensional line exist in the first dimension (1-D length), circles and other 2-D objects exist in the second dimension (length and width), cubes exists in the third dimension (length, width and height) and matter exists in the fourth dimension (length, width, height and mass. The great omnipresent dimension is and always will be a mystery. See table 1.

We can observe numbers, first, second and third dimensional objects with our imagination(mind), while we can observe matter with our fourth and fifth dimensional anatomy- our physical bodies and our fifth dimensional mind. String theory has proposed multiple dimensions which may give further evidence for the merger of reductionism and wholism as world views.

According to many nature based cultures, some of the phenomena that are observed at the subatomic level can also be observed at the classical, Newtonian level. This means that relativity, quantum mechanics and string theory may provide the modern scientific evidence for nature based, traditional technologies.

It may be that our ethereal bodies like the luminous energy field and chakra system can interpret energies from the fifth and higher dimensions. We may be able to 'see' energies with our open third eye (dreaming or awake), 'hear' voices from the fifth and other dimensions with our open third and fourth ears of our luminous energy field. This shift of consciousness from the fourth dimension to the fifth might be as challenging as the paradigm shift of moving from a 2-dimensional flat globe to a 3-dimensional one.

Since the equation $\mathbf{E}=\mathbf{m} \mathbf{C}^{\mathbf{2}}$ is stating that matter is energy and energy is matter, this may be evidence of 'the matter cycle'. Just as there is a water cycle, and a rock cycle, matter and the energy of consciousness may cycle in and out of human form. Universal Energy may slow down to below the speed of light squared transforming into matter.

I hypothesize that our consciousness and physical bodies are energy, the energy cannot be created nor destroyed. This concept is aligned with the first law of thermodynamics which states that energy cannot be created nor destroyed, but transformed. Our organized metaphysical light bodies (spirits) which exist in $5^{\text {th }}$ or higher dimensions are responsible for ordering the subatomic particle into a specific pattern that is the human mind/body. This idea is the same as reincarnation that is mentioned in many spiritual texts.

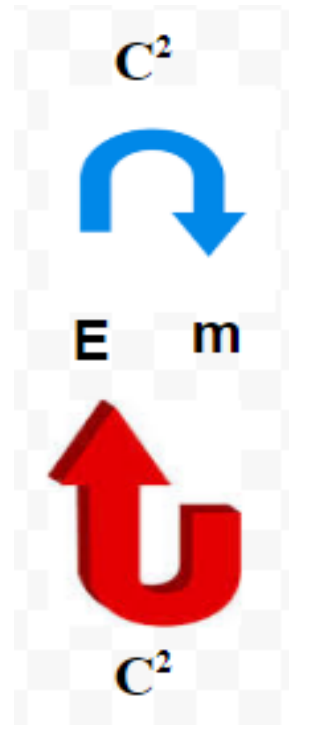

Figure 6 The Matter Cycle

Mathematically we can prove that One and 1 are the same concept, while creating a new field of metaphorical mathematics. With the concepts of unitizing, abstraction and one-to-one correspondence, the number 1can represent whatever one wishes [30]. Similarly, with the concepts of relativity, metaphor and mystery, One can be whatever one wishes (e.g., Objective, neverbeginning energy.) By transitive relation, if One can be whatever one wishes and 1 can be whatever one wishes, then One $=1$. This proof creates the field of metaphorical mathematics. Further to this, we can argue that numbers tell 'stories' in that number concepts like counting can be represented with letters. In the binary system only 1 and 0 are used. We could substitute letters A and O. A could represent the number 1 for two reasons. The first is that $\mathrm{A}$ is the $1^{\text {st }}$ letter of the alphabet and the second is that the letter A sometimes represents the number 1 e.g., please pass me a book. The number 0 can be represented by the letter $\mathrm{O}$ for a number of reasons. One is that they both look alike and the other is that $\mathrm{O}$ appears in words that represent the concept zero. e.g., none, no nothing and zero. If we used binary counting and letters to represent numbers, numbers could be seen as telling stories.

Another way to view numbers as relative vs absolute is to see them with respect to the concept of infinity which goes on forever. This means that all numbers contain an element of infinity and go on forever.

As the previous examples show how we can merge and relate different ways of knowing, the results of the convergence of Earth ways of knowing 
and the modern scientific way of knowing can be applied to create a more wholistic view of what it means to be educated.

The Rotman I-Think program motivated me to use the tension created by the binary epistemologies to create a new way of knowing. As such, I use a Pro/Pro chart here to demonstrate the beneficial characteristics of both modern and ancient science. See table 2.

Table 2 Pro/Pro Proposing ...

\begin{tabular}{|l|l|}
\hline Modern Science & Ancient Science \\
\hline Reductionist & Wholistic \\
\hline Innovative process & Innovative process \\
\hline Focus on 1 & Focus on One \\
\hline Scientific method & Relativistic method \\
\hline Absolute 0 & Zero Point Field \\
\hline Human-design focus & Nature-design focus \\
\hline $\begin{array}{l}\text { Knowledge archived in } \\
\text { libraries }\end{array}$ & $\begin{array}{l}\text { Knowledge archived in } \\
\text { Elders }\end{array}$ \\
\hline Print literacy focus & Oral story telling focus \\
\hline Experimental & Experiential \\
\hline Algorithmic & Circadian Rhythmic \\
\hline
\end{tabular}

This poetry further expresses this idea of wholism.

\section{Heineken and a Dance}

Verse

$i$ finally found the bridge to the town Don't remember but it is profound. At the start, is the journey of the heart that knows it

And still, allowing Me-Mees to fall. The seasons give me reasons to grow And so, what i see is what i know. What I feel is what I know. The feeling is a f.e.a.r. and a fact, That turns into a binding contract. It turns into a binding contract.

Chorus

So anytime you see me in a trance, you could say Heineken and a dance. You could say Heineken and a dance. At any time I'm in a in a trance, you could say Heineken and a dance. You could say Heineken and a dance.

Then all the Self and meee--e-ee We did agree to a split-psych-key And as $i$ feel the blee-ee-eed. I do remember that the Light doth feed. And to the Light We be G.O.D. speed. $\mathrm{Cuz}$ we the darkness that's in need. Yeah we the darkness that's in need. She is Wise-Love and I AM Her. So I'm grateful that we now concur. Yeah I'm grateful that we now concur.

Chorus
So anytime you see me in a trance, you could say Heineken and a dance. You could say Heineken and a dance. At any time I'm in a in a trance, You could say Heineken and a dance.

You could say Heineken and a dance.

Bridge

At times i push pull away Sometimes i wish she would stay Sometimes i push pull away, At times I wish you would stay.

Chorus

So any time you see me in a trance, you could say Heineken and a dance. You could say Heineken and a dance At any time I'm in a in a trance, you could say Heineken and a dance. You could say Heineken and a dance.

\section{A New Education for a New Earth- Inclusive Education Process}

My conception of inclusive education was partly informed by my apprenticeship as ashaman as well as courses on spirituality and education. The word 'process' is used toencourage a mind-set of lifelong learning. I defined the Inclusive Education Process as:

The continuous innovation, improvement and application of strategies and technologies that are employed to enhance well-being and achievement levels, by integrating the mind, body, psyche and spirit. It is learning for all, which includes learning of all and learning as all.

The body, mind, psyche and spirit can be likened to four directions of a medicine wheel. See figure 6 .

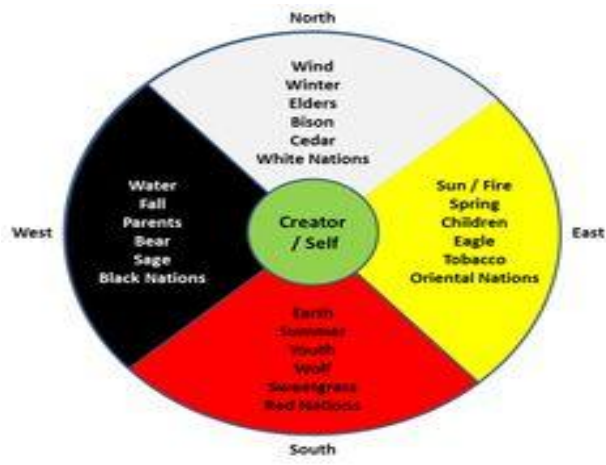

Figure 6. A Medicine Wheel

The founder of the Four Winds Society and author of the book Shaman, Healer, Sage, Alberto Villoldo makes a distinction between body, mind, psyche and spirit. They are seen as Russian nested dolls, where the mind informs the body, the soul informs the mind and the spirit informs the soul. The 
language of the body is biochemical, the language of the mind is words and emotions, the language of the soul is archetypes and the language of spirit is energy. ${ }^{13}$ As such, the Lead Learners of the Inclusive Education Process are mindful of all levels of our being and employ teaching and learning strategies that speak to the whole student. The Inclusive Education Process sees the child as an individual genius human being with life-purpose, dreams, goals, feelings and interests, as opposed to an empty vessel who is filled by 'covering curriculum' while doing enough assessment to 'cover your ass'. Some Inclusive Education Process strategies include ceremonial rites of passage, working with dreams, nature, vision quests, visualization, mindfulness, positive affirmations, high expectations, fostering resilience, keystone approaches, Multiple Wisdoms, contemplative practices and energy medicine.

\section{Dreams}

Many indigenous cultures believe that the dream state is a real state and more important than the awakened state. Some tribes say that dreams are the Creatorc ommunicating with us. Nightly dreams can be used in education in a number of ways.

They can be used as idea generation for authoring topics. One student I taught complained about nightmares. I encouraged her to draw the character in her nightmare and to create a story using it as a villain. She drew the character, but didn't author the story and it seemed to have some effect. Dreams can be a valuable tool for creative writing as well as healing. Nightly dreams can also be used to enhance our self-awareness.

The Senoi are an indigenous tribe that lives in Central Malay Peninsula. They believe that humans create images of the physical world as part of an adaptive process. Some of the images may be in conflict and once internalized, the images turn humans against themselves and others. If not resolved, this conflict makes us physically, emotionally, psychologically and spiritually ill [14].

Resolving or completing dreams can be done with lucid dreaming or visualization and is a useful technique for enhancing executive function and for transmuting the unmanifest into physical form. Visionaries including Mahatma Gandhi and Martin Luther King Jr. used dreams, meditation and visualization to change the world.

\section{Ceremonial Rites of Passage}

In the book King, Warrior, Magician, Lover, Moore and Gillette write "If contemporary men can take the task of their own initiation from Boyhood to Manhood as seriously as did their tribal forebears, then we may witness the end of the beginning of our species, instead of the beginning of the end [20]"
Ceremonial rituals and rites of passage are used in indigenous cultures to mark transitions.

Rituals like opening circles at the beginning of the day and closing circle at the end of the day are very powerful ways of building group cohesion and a climate of openness and trust. Circles may also be used to resolve conflicts and enhance academics. Rites of passage are used to mark major life changes like puberty.

\section{Contemplative Practices}

Contemplative practices can be integrated in education to enhance the well-being and achievement of the whole child. There are a number of contemplative strategies that are currently in use in education, including mindfulness, yoga and tai chi. These practices help to build focus and attention, innovation, self-regulation, organization, resilience, collaboration, cognitive ability, gratitude, higherorder thinking, and critical thinking skills. Two of the core practices that are common to all these strategies are focused-awareness and attention to the breath. As the pace of modern society growsmore frenetic, the rates of stress and related disorders are on the rise. These contemplative practices have been used for thousands of years and are effective in reducing stress and anxiety. Reducing and optimizing stress is known to impact neuronsin the amygdala, enhancing communication to the prefrontal cortex and improving cognitive ability [17].

\section{Fostering Resilience}

Resilience is known as the ability to bounce back from challenges faced in life. Are silience focus as opposed to an 'at risk' focus can provide different outcomes. Some characteristics of resilient persons and communities include social competence, compassion, problem solving, autonomy, humor, internal locus of control, and a sense of life purpose. In order to foster resilience in communities, caring relationships, high expectations and opportunities for contribution are the protective factors that are Essential [18].

Some of the ways to nurture caring relationships are by being present, being trustworthy, paying mindful attention, showing interest offering loving support, listening without judgment, demonstrating patience, and recognizing strengths and dreams.

Maintaining high expectations include having faith in people, guiding without coercion, performing rituals and rites of passage and focusing on strengths. Resilient communities are able to create and maintain a loving world for us all. There are many indigenous and modern strategies to help us create peace in our hearts, so as to extend this to our communities. 
The Munay $\mathrm{Ki}$, which are the initiation rites of the Laika tribe of Peru are one such way of reengineering our luminous energy field so as to become more compassionate. Another example of a modern strategy is Heart Math - The Science of the Heart. The Institute of Heart Math has conducted research on the role of the human heart in performance. One of the striking findings is that the heart emits an electromagnetic field which can impact the brain waves and cognitions of others within its range [19]. Incorporating such strategies into education will be instrumental in redefining what it means to be educated.

\section{Energy Medicines}

Medicines like indigenous medicines, acupuncture, ayurveda, homeopathy, reiki, drums, qigong and others can be integrated into modern education in order to enhance the well-being and achievement of our world. Many of these practices can be used to maintain well-being and espouse a preventative model. Since an ounce of prevention is worth a pound of cure, students will learn to use these and other simple strategies, like sleep hygiene, diet and the power of gratitude to support integrative well-being. Through the health curriculum, students can learn about the luminous energy field, the chakra system and the impact these parts of their anatomies have on maintaining sound overall health.

\section{Keystone Proactive Approaches}

Dr. Joe Ducharme at the Ontario Institute for Studies in Education researches strategies that shape students' identities over time. Some strategies involve providing praise and support, then gradually fading the level of support as students' progress. Students then self-identify as successful and may be better at self-regulation.

\section{Multiple Intelligences to Multiple Wisdoms}

Howard Gardner developed the theory of Multiple Intelligences. He outlined that we all are intelligent in different ways and defined nine different intelligences including logical/mathematical, visual/spatial, rhythmic/musical, verbal/linguistic, kinesthetic, intrapersonal, interpersonal, naturalistic, and existential. The main idea is asking not how smart we are but how we are smart. I have conceptualized multiple wisdoms so as to merge the mind and the heart and ask how we are 'smheart'. The word 'smheart' would be asynonym of wisdom in that it is the intelligence of the mind combined with the compassion of the heart. I expect that more wisdoms will be added to the list of multiple wisdoms which represent the rich diversity of the cultures on our planet.

The inclusive educator responds to the learner with an open heart and mind, as well as an understanding of the world the child is growing into. She sees reading and writing as one form of literacy and is aware that other cultures developed other forms of non-print literacy and ways of knowing which are equally valuable to humanity. My hope is that we look at IQ as the Inclusivity Quotient instead of the Intelligence Quotient. As a result, we would be equally interested in the Emotional Quotient, Physical Fitness, and Metaphysical Quotient. The Metaphysical Quotient will not be an actual score, but a descriptive and self-reflective assessment of the level of meaning and purpose in one's life. Since everyone has a unique purpose for coming to this planet, education will intend to discover what each individual's genius is, and allow this genius to shine in the world. This freedom to self-actualize will result in a new economy for a new earth.

\section{Conclusion}

The time has come for empirical algorithms to merge with indigenous rhythms. The Mayans and many other indigenous cultures cite this time in human history as unprecedented. It is prophesized that we are currently undergoing an evolutionary leap and it will be easier to embody an evolved consciousness. A new form of light is thought to be entering Earth's atmosphere. This light is transforming those who are ready. This could be what the Bible may have been referring to, as it states in Peter 3:10:

But the day of the Lord will come like a thief.

The heavens will disappear with a roar; the

elements will be destroyed by fire, and the earth and everything done in it will be laid

bare.

This destruction by fire may not be a literal one, but a metaphysical one. The fire may be the new light that has to power to transform our DNA and our collective unconscious. This transformation will lead us to become more loving, patient, forgiving, kinder, inclusive, faithful, compassionate, peaceful, mindful, grateful, reliable, psychic human beings. The Inclusive Education Process will look at various indigenous pistemologies from around the world and how they can be merged with modern education. The results of this research are intended to impact the process of unification of global education.

The Inclusive Education Process combines traditional and modern ways of knowing. It can play a vital role in preparing and guiding humanity as we continue on our transformative heroic journeys towards a perpetually, prosperous and peaceful planet. I conclude with a poem that expresses this 
vision. It is a conversation between Pacha Mama and the Creator. They are speaking of making Love. We all are the Love- the children of this blessed union.

\section{A Peaceful Planet}

Verse

Pacha Mama you look fine, I was thinkin' I wanna serenade and know what you drinkin'?

I like to love your lyrics you mysterious one.

You DouxDoux remind me of le Phantome.

You know I'm drinkin' rain, as long as you buyin'.

An' I'm'ma dance my dance cuz I know that you spyin'.

Dance you say? You read my soul and my mind.

I love to feel your groove, we can dance any

kind.

Chrous

Can I get a peace?

You can get a peace.

I can get a peace?

Yeah you can get a peace.

A peaceful planet

Are we there yet?

A peaceful planet!

Are we there yet?

A peaceful planet!

Verse

To you Big Daddy, I give gratitude.

You so welcome honey, and love your attitude.

You and I together, we always create.

And I'm so happy that peace is our fate.

I heard a rumour, to you I need to pray.

Just remember honey that you also need to play

Speakin' of play, I hear you's a playa.

Have some faith girl and come to m' laaair

Chrous

So can I get a peace?

You can get a peace.

I can get a peace?

Yeah you can get a peace.

A peaceful planet

Are we there yet?

A peaceful planet!

Are we there yet?

A peaceful planet!

Bridge

And turn Mama, turn Mama turn

'Tis the season to learn Mama, learn Mama

learn

The Rhythm Book let it burn, let it burn, let it burn

Just wait until it's our turn, it's our turn, it's our turn

Chrous

So can I get a peace?

You can get a peace.

I can get a peace?

Yeah you can get a peace.

A peaceful planet
Are we there yet?

A peaceful planet!

Are we there yet?

A peaceful planet!

\section{References}

[1]. U2, (1991). One. Lyrics by Bono music by U2. From the CD 'Mysterious Ways'

[2] Schwartz, S., (1995). Colours of the Wind [Recorded by Vanessa Williams]. From the Walt Disney Records Soundtrack of the film Pochahontas. U.S.A.

[3]Boekhoven, J., (2011). Genealogies of Shamanism. Barkhuis, 179.

[4] National Collaborating Centre for Aboriginal Health. (2013). Improving Population Health, Health Promotion, Disease Prevention and Health Protection Services and Programs for Aboriginal People.

[5] Bone, H., Courchene, D; Greene R., (2012). The Journey of the Spirit of the Red Man. Trafford, 3

[6]. Gracey, M., \& King, M. (2009). Indigenous health part 1: Determinants and disease patterns. The Lancet, 374: 6575

[7] The Natural Medicine Guide to Schizophrenia, or The Natural Medicine Guide to Bi-polar Disorder, pages 178189, Stephanie Marohn (featuring Malidoma Patrice Somé)

[8] Aronowitz, S., Giroux, H.A., (1990). Postmodern Education Politics, Culture and Social Criticism. Minneapolis, Minesota: Universityof Minnesota Press.

[9] Apple, Michael W. "Ideology, Reproduction, and Educational Reform." Comparative Education Review (1978): 380. Print.

[10] Forest, O. S., (2000). Dreaming the Council Ways: True Native Teachings from the Red Lodge. York Beach, Maine: Samuel Weiser Inc.58.

[11] De Saint Exupery, A., (1943). Le Petit Prince. Running Press Book Publishers. 65.

[12] Tolle, E., (2009). A New Earth. Penguin Books Limited. 5, 306.

[13]Villodo, A. (2000) Shaman, Healer, Sage. Harmony Books. 146.

[14] Hendricks G., Wills, R., (1975). The Centering Book: Awareness Activities for Children, Parents and Teachers. Prentice Hall. 57

[15] H. McBratney, Personal communication, (August 15, 2012)

[16] Kim, P., Evans, G., Angstadt M., Ho. S., Sripada C., Swain J., Liberzon, I., Phan., K., (2013). Effects of 
childhood poverty andchronic stress on emotion regulatory brain function in adulthood. Proceedings of the National Academy of Sciences of the UnitedStates of America

[17] The Hawn Foundation, (2011) Mind Up curriculum K-2. Scholastic Teaching Resources. 13

[18] Cohen, L. Chavez, V, Chehimi, S., (2010) Prevention is Primary. Jossey-Bass.

[19] Heart Math (2009) The Science of the Heart. https://www.heartmath.org/resources/downloads/scienceof-the-heart (Access date: 16 December, 2015)

[20] Harper, San Franciso, (1990) King Warrior Magician Lover, Rediscovering the Archetypes of the Mature Masculine. 56, 156.

[21] Hay House Inc., Carlsbad CA (2010) Mystery of the White Lions. 215.

[22] CMEA (2009) Exploring Social Justice. 212

[23] Dolphijn,R. \& van der Tuin, I.(Eds.) (2012). New Materialism: Interviews and Cartographies. Ann Arbor: Open Humanities Press.66

[24] Emeagwali,G., and Shizha, E., (Eds.) (2016). African Indigenous Knowledge and the Sciences: Journeys into the Past and Present: Sense Publishers.7

[25]Murray, L.J. \& Rice, K. (Eds.) (1996) Talking on the Page: Editing Aboriginal Oral Text. University of Toronto Press, Scholarly Publishing Division; 1 edition (July 26 1999)

[26] Lipton, B. (2005) Hay House Inc. The Biology of Belief. 120

[27] Ontario Ministry of Education, (2013). Capacity Building Series, K-12. (2013). Culturally Responsive Pedagogy Towards Equity and Inclusivity in Ontario Schools, http://www.edu.gov.on.ca/eng/literacynumeracy/ inspire/research/CBS_ResponsivePedagogy.pdf (Access date: 3 March, 2015)

[28] (]Mind and Life Institute) (September 21, 2013) Mind and Life XXVI[Video file] YouTube. Retrieved from https://www.youtube.com/watch?v=n984nd55BqQ

(Access date: 6 February, 2015)

[29] Bhaerman S., Lipton, B., (2009) Hay House Inc. Spontaneous Evolution. 321

[30] Ontario Ministry of Education, (2003). A Guide to Effective Instruction in Mathematics- Kindergarten to Grade 3, Number Sense and Numeration, retrieved from http://www.edugains.ca/resourcesLNS/GuidestoEffectiveI nstruction/GEI_Math_K3/K_3_NumberSenseNumeration. pdf. 8 (Access date: 12 March, 2015) 